\title{
Selected Approaches for Testing Asset Pricing Models Using Polish Stock Market Data
}

\author{
Anna Czapkiewicz*, Iwona Skalna*
}

\begin{abstract}
The main objective of this paper is to discuss alternative methods for testing the Fama-French (FF) three-factor asset pricing model. The properties of the selected methods are compared through a simulation study. The main stress is put on the behaviour of the selected methods for small samples. The parameters used in the simulation study are obtained on the basis of real data coming from the Polish stock market (Warsaw Stock Exchange). Different sample characteristics such as homoscedasticity, conditional heteroscedasticity and autocorrelation as well as heteroscedasticity are tested.
\end{abstract}

Keywords: Fama-French three-factor model, systematic risk, risk premium, Warsaw Stock Exchange, small sample problem

Mathematics Subject Classification: 62

JEL Classification: C31

Revised: November 4, 2014

\section{INTRODUCTION}

The cross-sectional differences in asset expected returns have attracted considerable attention in finance literature. Eugene Fama and Kenneth French $(1993,1996)$ had investigated the explanatory power of certain factors associated with a company's characteristics, such as size, book-to-market ratio or leverage. Based on their observations, they designed a three-factor model for explaining stock excess return. The three-factor model expands the classical CAPM model by adding to the market risk (RM) factor two additional factors: SMB (small minus big capitalization) factor and HML (high minus low book-to-market ratio) factor.

In the literature on solving asset pricing models, a vast amount of methods for the estimation of unknown parameters in the cross-sectional differences in asset expected returns can be found. However, because only asymptotic statistical properties of those methods are well-known, therefore selection of a suitable methodology poses a problem,

* AGH University of Science and Technology, Faculty of Management, Poland, e-mail: gzrembie@cyf-kr.edu.pl, corresponding author, iskalna@zarz.agh.edu.pl 
especially when only a small amount of data is available. This problem is faced when dealing with emerging markets. Then, the verification of the significance of the risk premium is very difficult.

The most promising approach for estimating and testing asset pricing models that has been widely used in the literature is the two-pass regression method first used by Jensen, Black and Scholes (1972) and Fama and MacBeth (1973). The two-pass regression model (OLS or its generalized version GLS) is simple but suffers from the errors-in-variables (EIV) problem.

In addition to the two pass approach, the maximum likelihood method (ML) and generalized method of moments (GMM) are explored in the financial literature. The ML is useful because it is asymptotically efficient under the classical independent and identically distributed multivariate normal returns assumptions. This method was proposed by Gibbons (1982) to solve the errors-in-variables problem. In the case of one factor model, the formula for ML estimators was developed by Kim (1995). This method was also discussed by Chen and Kan (2004). The ML method reduces the EIV problem, but it is sensitive to the number of observations.

The generalized method of moments (GMM) due to Hansen (1982) have been also considered for estimating asset pricing models. The main advantage of the GMM is that it can easily accommodate serial correlation and conditional heteroscedasticity in the joint distribution of returns and factors. However, it also suffers from poor small sample performance. Generally, the small-sample properties of the above estimators make the asset pricing research on emerging markets very difficult. Simulation studies performed, e.g., by Amsler and Schmidt (1985), Chen and Kan (2004), and Shanken and Zhou (2007) give some insights into the problem. Shanken and Zhou (2007) investigated the small-sample properties of the ML, GMM and some variants of two-step cross-sectional expected return estimators under the assumption that data-generating process has the standard multivariate normal distribution or multivariate t-distribution with 8 degrees of freedom. They used data coming from the US stock market in the simulation study.

The present work verifies the effectiveness of the above mentioned methods for testing FF model on the Polish stock market (Warsaw Stock Exchange - WSE). The simulation study is performed to investigate the finite-sample properties of various procedures for testing the Fama-French three-factor pricing model. The data used is obtained from the Warsaw Stock Exchange from December 2002 until March 2012. An attempt is made to compare the OLS, GLS, ML and GMM methods under several restrictions imposed by emerging market characteristics such as a small number of portfolios that can be constructed from available data and the calibration of portfolio construction parameters based on a relatively small sample. Moreover, three different data-generating processes are used in the simulation study: the standard multidimensional normal distribution, multidimensional t-Student distribution and the $\operatorname{VAR}(1)$ process.

The paper has the following structure. Section 2 presents a general econometric cross-sectional asset pricing model and the methodology used to estimate its parameters. The empirical study is described in Section 3. The paper ends with concluding remarks and recommendations for future work. 


\section{THEORY AND METHODOLOGY}

According to a $K$-factor asset pricing model, the expected return on a portfolio in excess of the risk-free rate is explained by the sensitivity of its return to $K$ common factors. The expected excess returns satisfy the linear relationship that can be written in a matrix form as:

$$
E\left(R_{t}\right)=\gamma_{0}+\gamma_{1} \beta_{1}+\ldots+\gamma_{K} \beta_{K}
$$

where $\gamma_{1}, \ldots, \gamma_{k}$ are defined as expected risk premiums. The vector $R_{t}=$ $\left(R_{1 t}, \ldots, R_{N t}\right)$ of $N$ portfolio excess returns at time $t$ fulfils the following multiple equation model:

$$
\epsilon R_{t}=\alpha+\beta_{1} f_{1 t}+\ldots+\beta_{K} f_{K t}+\epsilon_{t}, t=1, \ldots, T
$$

where $f_{1 t}, \ldots, f_{K t}$ are common factors' values at time $t, \alpha, \beta_{1}, \ldots, \beta_{K}$ denote $N$-dimensional vectors of factors' sensitivities or loadings and $\epsilon_{t}=\left(\epsilon_{1 t}, \ldots, \epsilon_{N t}\right)^{T}$ is a vector of error terms at time $t$. The covariance matrix of $\epsilon_{t}$ is denoted by $\Sigma$. To simplify the notation, the vector of unknown risk premium parameters $\left.\gamma_{0}, \gamma_{1}, \ldots, \gamma_{K}\right)^{T}$ is denoted by $\gamma$. The discussion focuses on the case where $\beta=\left[\beta_{1}, \ldots, \beta_{K}\right]$ is the same throughout the entire sample period.

\subsection{SOME METHODS UNDER CONDITIONAL NORMALITY ASSUMPTION}

The simplest and the most popular method for estimating and testing asset pricing models is the two-pass cross-sectional time series regression. In the first pass, betas of the tested portfolios are estimated using the least squares regression of returns $R_{i t}(i=1, \ldots, N)$ on $K$ common factors $f_{1 t}, \ldots, f_{K t}$. In the second pass, gammas $\left(\gamma_{0}, \gamma_{1}, \ldots, \gamma_{K}\right)^{T}$ are estimated by cross-sectional regression of the mean vector estimate, $E\left(R_{t}\right)$, on the betas estimates $\hat{\beta}_{1}, \ldots, \hat{\beta}_{K}$ obtained from the first pass. The unknown gammas estimates $\widehat{\gamma}$ are calculated from the ordinary least squares (OLS) regression:

$$
\widehat{\gamma}=\left(X^{T} X\right)^{-1} X^{T} \bar{R}
$$

where $\bar{R}=\left(\bar{R}_{1}, \ldots, \bar{R}_{N}\right), X=\left[1_{N}, \hat{\beta}\right]$ and $\hat{\beta}=\left[\hat{\beta}_{1}, \ldots, \hat{\beta}_{K}\right]$. Taking into account error terms covariance matrix $\Sigma$, the generalised least squares (GLS) regression yields the estimates:

$$
\widetilde{\gamma}=\left(X^{T} \widehat{\Sigma} X\right)^{-1} X^{T} \widehat{\Sigma}^{-1} \bar{R}
$$

where $\widehat{\Sigma}$ is an estimate of $\Sigma$.

Since in the second stage of the testing procedure betas estimates are used instead of the real values, therefore the errors-in-variables problem occurs. When error terms $\epsilon_{t}$ are assumed to have the multidimensional normal distribution, it is possible to correct the variance of the estimators (Shanken (1992). The error-in-variables problem can be also reduced using the maximum likelihood estimator. The analytical form of ML estimates was obtained by Chen and Kan (2004). 
Let $x=\left(x_{0}, x_{1}, \ldots, x_{K}\right)$ be an eigenvector associated with the largest eigenvalue of the matrix $A^{-1} G$, where:

$$
G=\left[\begin{array}{lll}
1 & 0 & \mathbf{0}^{T} \\
0 & 0 & \mathbf{0}^{T} \\
\mathbf{0} & \mathbf{0} & \hat{V}^{-1}
\end{array}\right]
$$

and $A=\left[\bar{R}, 1_{N}, \hat{\beta}\right]^{T} \widehat{\Sigma}^{-1}\left[\bar{R}, 1_{N}, \hat{\beta}\right]$. Then, the maximum likelihood estimate of $\gamma$ is given by:

$$
\widehat{\gamma}=\left(-\frac{x_{1}}{x_{0}}, \ldots,-\frac{x_{K}}{x_{0}}\right)
$$

Though the ML approach reduces the errors-in-variables problem, the finite sample properties problem is still present. Chen and Kan (2004) proved that the mean and variance of the ML do not exist for finite samples

\subsection{THE GMM APPROACH}

The more general approach, than the two-stage cross sectional regression and ML, to estimating asset pricing model parameters is the generalized method of moments (GMM) due to Hansen (1982). This approach does not require the assumption of normality of returns and is robust to both conditional heteroscedasticity and serial correlation in model residuals as well as in factors. Note that in the case of homoscedasticity in the model (2), unknown parameters estimates provided by the GMM method are numerically identical to ML estimates.

When heteroscedasticity and autocorrelation of residuals are present in the model, the computations are numerically more complicated due to the large number of parameters to be estimated and the nonlinearity of a model. As shown by Shanken and Zhou (2007), numerical solutions might not converge. Therefore, the classical GMM is rarely used in practice. Instead, to simplify calculations, the two-step GMM procedure suggested by Cochrane $(2001)^{1}$ can be used. Consider the partition of unknown parameter vector $\varphi=\left(\alpha^{T}, \beta_{1}^{T}, \ldots, \beta_{K}^{T}, \gamma^{T}\right)$ into two sub-vectors $\varphi=\left(\varphi_{1}, \varphi_{2}\right)$ where $\varphi_{1}=\left(\alpha^{T}, \beta_{1}^{T}, \ldots, \beta_{K}^{T}\right)$ and $\varphi_{2}=\gamma^{T}$. Let then:

$$
\mathbf{g}_{\mathbf{t}}(\varphi)=\left[\left(\epsilon_{\mathbf{t}}\left(\varphi_{\mathbf{1}}\right) \otimes\left(\begin{array}{c}
\mathbf{1} \\
\mathbf{F}_{\mathbf{t}}
\end{array}\right)\right)^{\mathbf{T}},\left(\left(\mathbf{R}_{\mathbf{t}}-\left[\mathbf{1}_{\mathbf{N}}, \beta\right]\right) \gamma\right)^{\mathbf{T}}\right]=\left[\mathbf{g}_{\mathbf{1 t}}\left(\varphi_{\mathbf{1}}\right), \mathbf{g}_{\mathbf{2} \mathbf{t}}(\varphi)\right]
$$

and $\mathbf{g}_{\mathbf{T}}(\varphi)=\left[\mathbf{g}_{\mathbf{1}}\left(\varphi_{\mathbf{1}}\right), \mathbf{g}_{\mathbf{2}}(\varphi)\right]=\frac{\mathbf{1}}{\mathbf{T}} \sum_{\mathbf{t}=\mathbf{1}}^{\mathbf{T}} \mathbf{g}_{\mathbf{t}}(\varphi)$. The two-step GMM approach requires the relevant moment conditions to be satisfied:

$$
\mathbf{E}\left[\mathbf{g}_{1 \mathbf{t}}\left(\varphi_{\mathbf{1}}\right), \mathbf{g}_{\mathbf{2}}(\varphi)\right]=\left[\mathbf{g}_{\mathbf{1} \mathbf{T}}\left(\varphi_{\mathbf{1}}\right), \mathbf{g}_{\mathbf{2} \mathbf{T}}(\varphi)\right]=\mathbf{0}
$$

Detailed analysis of the equation (8) shows that the first part of the conditions is exactly identified. So, estimate $\hat{\varphi}_{1}$ is indicated definitely. The problem of determining

\footnotetext{
${ }^{1}$ Slightly different parameterization method was discussed in Shanken and Zhou (2007).
} 
$\varphi_{2}$ estimator reduces to the problem of finding a solution to the following minimization problem:

$$
\min _{\varphi_{2}} g_{2 T}\left(\hat{\varphi}_{1}, \varphi_{2}\right)^{T} W_{2 T} g_{2 T}\left(\hat{\varphi}_{1}, \varphi_{2}\right)
$$

where $W_{2 T}$ is a weighting matrix.

Following Ogaki (1993), the optimal weighting matrix is defined as:

$$
W_{2 T}=\left(\left[-D_{21} D_{11}^{-1}, I_{N}\right] S_{T}\left[-D_{21} D_{11}^{-1}, I_{N}\right]^{T}\right)^{-1}
$$

where $D_{i j}(i, j=1,2)$ is the respective block of the $N(K+2) \times(N+1)(K+1)$ dimensional matrix of the $g_{T}(\varphi)$ derivatives with respect to all parameters and $S_{T}$ is a consistent estimate of the moment conditions covariance matrix.

Under adopted assumptions in the asset pricing model $D_{21}$ in (10) is equal to zero, thus:

$$
W_{2 T}=\left(\left[0, I_{N}\right] S_{T}\left[0, I_{N}\right]^{T}\right)^{-1}=S_{2 T}^{-1}
$$

where:

$$
S_{2 T}=\Omega_{0}+\sum_{j=1}^{m} w(j, m)\left[\Omega_{j}+\Omega_{j}^{T}\right]
$$

$w(j, m)$ is Parzen (P) or Bartlett (B) kernel (Andrews, 1991) and:

$$
\Omega_{j}=\frac{1}{T} \sum_{t=j+1}^{T} h_{t} h_{t-j}^{T},(j=0,1, \ldots, m)
$$

Summing up, the constructed consistent estimate $\hat{\varphi}_{2}$ obtained via two step GMM estimator satisfies the minimum of the function:

$$
\min _{\varphi_{2}}\left(\bar{R}-\left[1_{N}, \hat{\beta}\right] \varphi_{2}\right)^{T} W_{2 T}\left(\bar{R}-\left[1_{N}, \hat{\beta}\right] \varphi_{2}\right)
$$

where $h_{t}$ in $(13)$ is defined as $h_{t}=\hat{\beta}\left(F_{t}-\bar{F}\right)+\epsilon_{t}$.

The two-step strategy decreases the efficiency of the GMM estimates. In order to attain the efficiency bound of the GMM estimator, thus obtained estimate $\hat{\varphi}_{2}$ was used in the simulation study as a starting point for the iteration. The second stage is iterated with the inverse of the long run covariance matrix until convergence. The matrix $\left(D_{22}^{T} W_{2 T} D_{22}\right)^{-1}$ is considered as the asymptotic covariance matrix.

\section{EMPIRICAL STUDY}

The usefulness of the described methods for estimating the risk premium parameters is analysed for the Fama and French model for the Polish market. 
According to the Fama and French asset pricing model, the expected excess returns satisfy the linear relationships which can be written in the form:

$$
E\left(R_{t}\right)=\gamma_{0}+\gamma_{R M} \beta_{R M}+\gamma_{S M B} \beta_{S M B}+\gamma_{H M L} \beta_{H M L}
$$

where the vector $R_{t}$ fulfills the following multiple equation model:

$$
R_{t}=\alpha+\beta_{R M} R M_{t}+\beta_{S M B} S M B_{t}+\beta_{H M L} H M L_{t}+\epsilon_{t}
$$

The simulation study was performed under the null hypothesis that asset pricing restrictions (15) are held. The input parameters used for the data-generating process were calculated on the basis of the original data. The simulation study was carried out for two sets of the data. Betas estimates $\hat{\beta}_{S M B}, \hat{\beta}_{R M}, \hat{\beta}_{H M L}$ and residuals $\epsilon_{t}$ were obtained from the time series regression (16) for the twelve portfolios created from real data of the period from December 2002 to March 2012 (Set I) and of the boom period only of the same time horizon (Set II). The validation of FF model in the boom period is discussed by Czapkiewicz and Skalna (Czapkiewicz and Skalna, 2011).

Table 1 presents the summary statistics for the factors from entire sample and from two joint boom periods that occurred between December 2002 and March 2012.

Table 1. Summary statistics for the factors

\begin{tabular}{lccc}
\hline & RM & SMB & HML \\
\hline Set I & & & \\
Average & 0.0046 & 0.0068 & 0.0067 \\
Standard deviation & 0.0690 & 0.0358 & 0.0367 \\
Set II & & & \\
Average & 0.0181 & 0.0101 & 0.0192 \\
Standard deviation & 0.0589 & 0.0331 & 0.0358 \\
\hline
\end{tabular}

It is worth to mention that the all means of the parameters in Set II are statistically significant, whereas the mean of RM in Set I is statistically insignificant. This fact will heavily influence the results of the simulation.

\subsection{SIMULATION STUDY}

In the simulation study carried out on the basis of the two sets of data - Set I and Set II, three different scenarios of the model assumptions were considered and in each scenario the properties of all estimators were examined for $T=60, T=120, T=240$, $T=480$, and finally for $T=720$.

The data used in the study were created as follows. In the first scenario, the vector $v_{t}=\left(R M_{t}, S M B_{t}, H M L_{t}, \epsilon_{1 t}, \ldots, \epsilon_{N t}\right)^{T}$ was generated from the multidimensional normal distribution. In the second scenario the $t$-distribution of $v_{t}$ was assumed. Hence, the heteroscedasticity was introduced to the model (16). In the third scenario, it was 
assumed that vector $v_{t}$ satisfies $\operatorname{VAR}(1)$ process, i.e., $v_{t}=\mu+A v_{t-1}+E_{t}$, where $E_{t}$ is the multidimensional $t$-distribution. For each scenario and also for each set and for each $T$, the simulation was run 100000 times.

During the simulation, the estimates of the parameters of the model (15) were calculated using the OLS, GLS, ML and GMM methods. The estimates obtained by the generalized method of moments under the assumption that the first order correlation in the data exists are denoted by GMM1lag. Additionally, the average and root-mean-square error (RMSE) were calculated based on the obtained results. For $T$ was really small T (see, e.g. Amsler and Schmidt (1985), Shanken and Zhou (2007)), the maximum likelihood estimates were extremely volatile, so theoretically unreliable values are not included.

Table 2 presents the results obtained for Set I and Set II and subsequent scenarios: multivariate normal distribution (the first scenario), multivariate $t$-distribution (the second scenario) and $\operatorname{VAR}(1)$ process (the third scenario); the input parameters were obtained from Set I and Set II. In the case of Set I, the estimated of the $\gamma_{S M B}$ and $\gamma_{H M L}$ parameters are very similar, thus Table 2 present only the results for the $\gamma_{S M B}$ parameter. On the other hand, for Set II, the results for the $\gamma_{H M L}$ parameter are presented, because they have the larger values.

Table 2. Pricing Intercept and Risk Premium Estimators in a three factor model

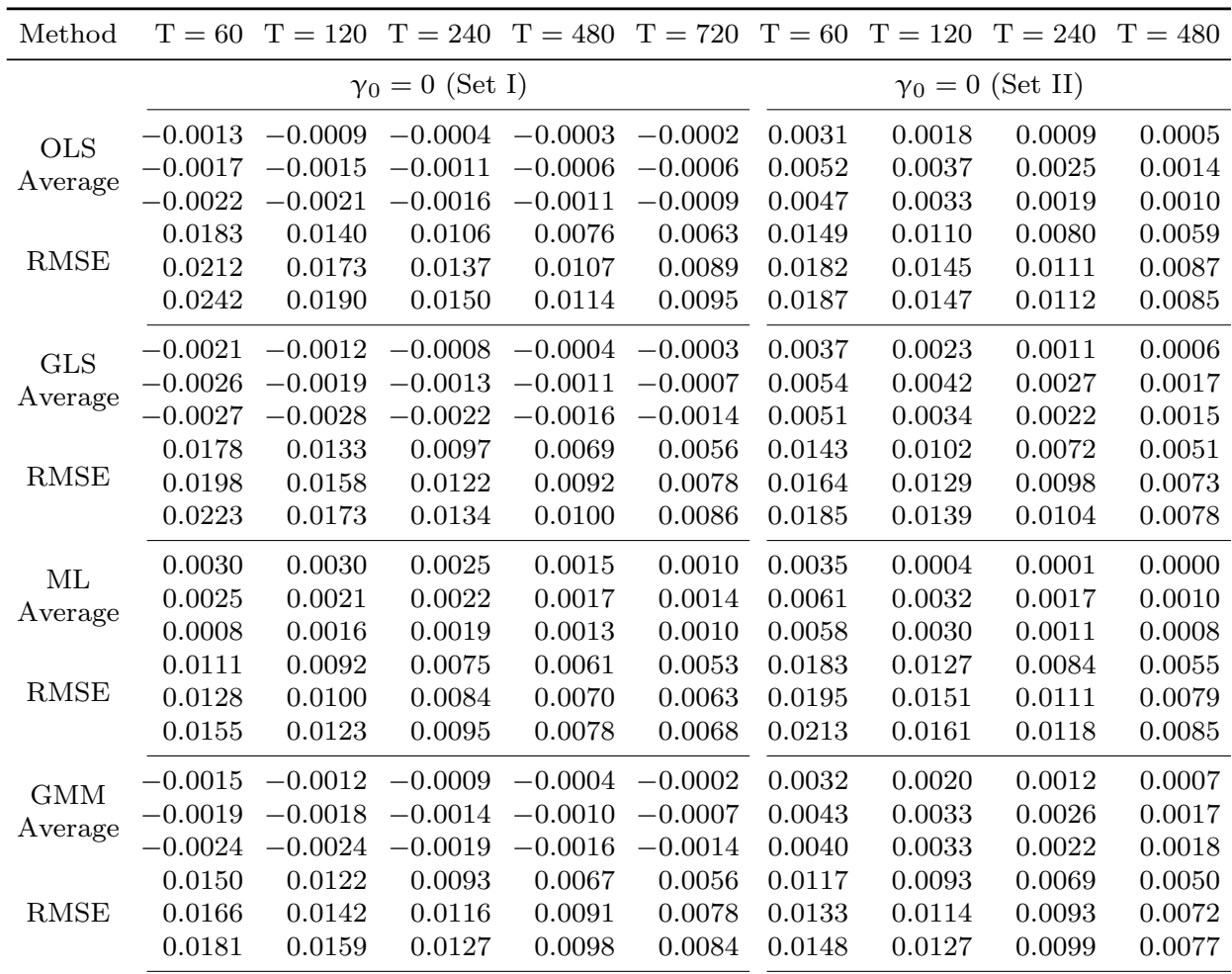


Table 2. cont.

\begin{tabular}{|c|c|c|c|c|c|c|c|c|c|}
\hline Meth & $=60$ & $\mathrm{~T}=120$ & $\mathrm{~T}=240$ & $\mathrm{~T}=480$ & $\mathrm{~T}=720$ & $\mathrm{~T}=60$ & $\mathrm{~T}=120$ & $\mathrm{~T}=240$ & $\mathrm{~T}=480$ \\
\hline \multirow[b]{2}{*}{$\begin{array}{l}\text { GMM1lag } \\
\text { Average }\end{array}$} & \multicolumn{5}{|c|}{$\gamma_{0}=0($ Set $I)$} & \multicolumn{4}{|c|}{$\gamma_{0}=0($ Set II $)$} \\
\hline & -0.0026 & -0.0024 & -0.0021 & -0.0017 & -0.0015 & 0.0031 & 0.0030 & 0.0022 & 0.0015 \\
\hline \multirow[t]{2}{*}{ RMSE } & 0.0155 & 0.0141 & 0.0120 & 0.0093 & 0.0079 & 0.0114 & 0.0109 & 0.0091 & 0.0070 \\
\hline & \multicolumn{5}{|c|}{$\gamma_{R M}=0.0046($ Set I $)$} & \multicolumn{4}{|c|}{$\gamma_{R M}=0.0181($ Set II $)$} \\
\hline \multirow{4}{*}{$\begin{array}{c}\text { OLS } \\
\text { Average }\end{array}$} & 0.0066 & 0.0056 & 0.0051 & 0.0050 & 0.0047 & 0.0145 & 0.0161 & 0.0171 & 0.0176 \\
\hline & 0.0067 & 0.0068 & 0.0060 & 0.0054 & 0.0053 & 0.0122 & 0.0141 & 0.0154 & 0.0167 \\
\hline & 0.0070 & 0.0069 & 0.0064 & 0.0060 & 0.0056 & 0.0130 & 0146 & .0160 & 0.0171 \\
\hline & 0.02 & & 0.0120 & 0.00 & & 0170 & & 0095 & 0071 \\
\hline \multirow[t]{2}{*}{ RMSE } & 0.02 & 199 & 0.0157 & 0.0121 & & 0214 & 172 & .0134 & 0.0102 \\
\hline & 0.0263 & 0.0211 & 0.0170 & 0.0129 & & 0.0202 & 0.0156 & 0.0118 & 0.0089 \\
\hline \multirow{4}{*}{$\begin{array}{c}\text { GLS } \\
\text { Average }\end{array}$} & 0.0070 & & 0.0056 & 0.0051 & & 0.0139 & 0.0155 & 0.0168 & 0.0175 \\
\hline & 0.007 & 0.0067 & 0.0061 & 0.0 & & 0.0120 & 133 & 0.0152 & 0.0163 \\
\hline & & 0.007 & 0.0068 & 0.0 & & & & 0156 & 0166 \\
\hline & & & & & & & & 088 & 0063 \\
\hline \multirow[t]{2}{*}{ RMSE } & & & 0144 & 0.01 & & & & 0120 & 0.0090 \\
\hline & & & 0.0159 & & & 0.0201 & & 0114 & 0.0085 \\
\hline \multirow{4}{*}{$\begin{array}{c}\text { ML } \\
\text { Average }\end{array}$} & & & & & & & & 0.0181 & 0.0181 \\
\hline & - & - & - & - & - & & & 162 & 171 \\
\hline & & & & & & 0114 & & 169 & 174 \\
\hline & & & & & & & & 103 & \\
\hline \multirow[t]{2}{*}{ RMSE } & - & - & - & - & - & 0.0236 & 185 & 0137 & 0.0097 \\
\hline & & & & & & 0.0233 & 0.0178 & 0.0130 & 0.0094 \\
\hline \multirow{3}{*}{$\begin{array}{c}\text { GMM } \\
\text { Average }\end{array}$} & & & & & & & & 167 & 173 \\
\hline & & & & & & & & 150 & 162 \\
\hline & & & & & & & & 157 & 165 \\
\hline \multirow{3}{*}{ RMSE } & & & & & & & & 088 & 063 \\
\hline & 227 & 180 & 0140 & 0.010 & 2 & & & .0120 & 0.0090 \\
\hline & 259 & 0207 & 0.0158 & 0.0120 & 0.0101 & 0.0204 & 0.0153 & 0.0115 & 0.0085 \\
\hline $\begin{array}{l}\text { GMM1lag } \\
\text { Average }\end{array}$ & 0.0076 & 0.0072 & 0.0068 & 0.0063 & 0.0062 & 0.0123 & 0.0139 & 0.0155 & 0.0165 \\
\hline \multirow[t]{2}{*}{ RMSE } & 0.0243 & 0.0195 & 0.0152 & 0.0114 & 0.0097 & 0.0192 & 0.0147 & 0.0110 & 0.0080 \\
\hline & \multicolumn{5}{|c|}{$\gamma_{R M}=0.0068($ Set I $)$} & \multicolumn{4}{|c|}{$\gamma_{R M}=0.0192($ Set II $)$} \\
\hline \multirow{4}{*}{$\begin{array}{c}\text { OLS } \\
\text { Average }\end{array}$} & & & & 0.0067 & & & & 188 & 0.0190 \\
\hline & & & & & & & & 181 & 186 \\
\hline & & & & & & & & 0183 & 0.0186 \\
\hline & & & 0.0023 & & & 0.0058 & 0042 & 0030 & 0.0021 \\
\hline \multirow[t]{2}{*}{ RMSE } & & & & & & & & 0044 & 0.0032 \\
\hline & 0.0074 & 0.0053 & 0.0038 & 0.0027 & 0.0022 & 0.0095 & 0.0069 & 0.0050 & 0.0035 \\
\hline \multirow{3}{*}{$\begin{array}{c}\text { GLS } \\
\text { Average }\end{array}$} & 0. & & & & & & & 0191 & 0.0192 \\
\hline & 0. & & 0.0067 & 0.0068 & & 0.0186 & & 0190 & 0.0190 \\
\hline & & & 0.0067 & & & 0.0185 & & .0188 & 0.0189 \\
\hline \multirow{3}{*}{ RMSE } & 0.0046 & 0032 & 0.0023 & 0.0016 & 0.0013 & 0.0054 & 0.0038 & 0.0027 & 0.0019 \\
\hline & & & & 0.0023 & & 0.0074 & & 0.0038 & 0.0027 \\
\hline & 0.0072 & 0.0051 & 0.0037 & 0.0026 & 0.0021 & 0.0093 & 0.0068 & 0.0048 & 0.0034 \\
\hline
\end{tabular}


Table 2. cont.

\begin{tabular}{|c|c|c|c|c|c|c|c|c|c|}
\hline \multirow{3}{*}{$\begin{array}{c}\text { ML } \\
\text { Average }\end{array}$} & 0.0065 & 0.0066 & 0.0068 & 0.0068 & 0.0068 & 0.0192 & 0.0192 & 0.0192 & 0.0192 \\
\hline & 0.0063 & 0.0065 & 0.0067 & 0.0068 & 0.0068 & 0.0190 & 0.0191 & 0.0191 & 0.0191 \\
\hline & 0.0059 & 0.0063 & 0.0064 & 0.0065 & 0.0066 & 0.0188 & 0.0190 & 0.0189 & 0.0191 \\
\hline \multirow{3}{*}{ RMSE } & 0.0046 & 0.0032 & 0.0023 & 0.0016 & 0.0013 & 0.0055 & 0.0038 & 0.0027 & 0.0019 \\
\hline & 0.0061 & 0.0045 & 0.0032 & 0.0023 & 0.0019 & 0.0077 & 0.0053 & 0.0038 & 0.0027 \\
\hline & 0.0065 & 0.0050 & 0.0034 & 0.0025 & 0.0021 & 0.0093 & 0.0066 & 0.0048 & 0.0033 \\
\hline \multirow{3}{*}{$\begin{array}{c}\text { GMM } \\
\text { Average }\end{array}$} & 0.0067 & 0.0068 & 0.0068 & 0.0068 & 0.0068 & 0.0188 & 0.0190 & 0.0191 & 0.0191 \\
\hline & 0.0067 & 0.0068 & 0.0068 & 0.0068 & 0.0068 & 0.0185 & 0.0188 & 0.0190 & 0.0191 \\
\hline & 0.0067 & 0.0068 & 0.0068 & 0.0068 & 0.0068 & 0.0184 & 0.0187 & 0.0189 & 0.0189 \\
\hline \multirow{3}{*}{ RMSE } & 0.0046 & 0.0032 & 0.0023 & 0.0016 & 0.0013 & 0.0053 & 0.0038 & 0.0027 & 0.0019 \\
\hline & 0.0064 & 0.0045 & 0.0033 & 0.0023 & 0.0019 & 0.0074 & 0.0052 & 0.0038 & 0.0027 \\
\hline & 0.0072 & 0.0050 & 0.0036 & 0.0026 & 0.0021 & 0.0093 & 0.0066 & 0.0048 & 0.0033 \\
\hline $\begin{array}{l}\text { GMM1lag } \\
\text { Average }\end{array}$ & 0.0066 & 0.0067 & 0.0068 & 0.0068 & 0.0068 & 0.0182 & 0.0189 & 0.0190 & 0.0191 \\
\hline RMSE & 0.0066 & 0.0047 & 0.0033 & 0.0023 & 0.0019 & 0.0083 & 0.0059 & 0.0042 & 0.0029 \\
\hline
\end{tabular}

In the case of Set I it can be noticed that for each scenario the estimates of $\gamma_{0}, \gamma_{H M L}$ and $\gamma_{S M B}$ obtained by OLS, GLS, GMM, GMM1lag methods are biased downward, The estimators of $\gamma_{R M}$ are biased upward and are characterized by huge values of the RMSE. The OLS estimator of $\gamma_{0}$ is the least biased, whereas the OLS estimators of $\gamma_{H M L}$ and $\gamma_{S M B}$ are the most biased compared to other methods. According to RMSE, the OLS is the least precise regardless the scenarios used. The smallest RMSE for $\gamma_{0}$ has the ML method, although it is biased upward. The ML method seems to be useless to estimate $\gamma_{R M}$ due to lack of numerical convergence. In the case of $\gamma_{H M L}$ and $\gamma_{S M B}$ estimations, the results of the ML method are similar to these of the GLS and GMM methods and all of them produce slightly downward biased estimators and their RMSE values are comparable. It is worth to note that in the case of the third scenario the ML estimator is more biased than those produced by the GLS and GMM methods.

The magnitude of RMSE dependent on the model assumption and for all the used estimators is the least in the first scenario and the biggest in the third scenario. When autocorrelation in (16) is taken into account, the GMM1lag estimator is definitely the most precise, except the estimator of $\gamma_{0}$, for which the ML method produces the best accuracy.

The results of the empirical study, when input parameters for the simulation study come from Set II, are also presented in Table 2. In this case, it can be concluded that properties of used estimators are the same for $\gamma_{S M B}$ and $\gamma_{H M L}$ parameters as in Set I. In contrary to Set I the different properties of the $\gamma_{0}$ and $\gamma_{R M}$ estimators is observed. It can be noticed that for all scenarios $\gamma_{0}$ parameter is heavily biased upward, whereas the risk premium values $\gamma_{R M}, \gamma_{H M L}, \gamma_{S M B}$ are slightly biased downward. For these parameters the difference between estimates average and real value is the smallest for the ML estimator, when $T>120$, regardless on the model assumption (For $T \leqslant 60$, ML turned out to be the most volatile and therefore practically useless) but this estimator produces the highest RMSE. The GLS and the GMM estimators are comparable according to their bias and RMSE. 
Similar to Set I case, for enough large sample (hence, for $T \geqslant 60$ in case of normality and for $T \geqslant 240$ in case of the second and third scenarios), the OLS estimator of $\gamma_{0}$ is less biased but also less precise than the GLS and the GMM estimators. The most precise estimator of $\gamma_{0}$ is the GMM, but in the third scenario the GMM1lag estimator is much more precise than others. For all used estimators of $\gamma_{0}$ their bias and RMSE values are the least in the first and the biggest in the third scenario.

For empirical purposes the conclusion about significance parameters is very important. Let us now consider the tests of the null hypothesis that a given parameter equals zero. The two-sided tests are taken into account and the nominal size of test is set at 5 percent. The test statistic for testing a null hypothesis is defined as the ratio of the estimate and its estimated standard error. The last parameter is adopted from the asymptotical properties of the used estimator. If the correction on the errors-in-variable problem (Shanken, 1992) is introduced to OLS or GLS variances, these test are denoted as OLS + Sh or GLS + Sh respectively. During the simulation study the percentage of null hypothesis rejections is summarized. The simulated rejection rates are presented in Table 3. The results for each scenario: normality. $t$-distribution and VAR(1) process, are presented in sequence similar to Table 2. The OLS method is also included to illustrate its properties.

Table 3. The rates of rejection of the null hypothesis.

The significance level is 5\%

\begin{tabular}{|c|c|c|c|c|c|c|c|c|c|}
\hline Method & $\mathrm{T}=60$ & $\mathrm{~T}=120$ & $\mathrm{~T}=240$ & $\mathrm{~T}=480$ & $\mathrm{~T}=720$ & $\mathrm{~T}=60$ & $\mathrm{~T}=120$ & $\mathrm{~T}=240$ & $\mathrm{~T}=480$ \\
\hline & \multicolumn{5}{|c|}{$\begin{array}{c}\text { Set I: Test the null } \gamma_{0}=0 \\
\text { when } \gamma_{0}=0\end{array}$} & \multicolumn{4}{|c|}{$\begin{array}{l}\text { Set II: Test the null } \gamma_{0}=0 \\
\text { when } \gamma_{0}=0\end{array}$} \\
\hline \multirow{4}{*}{ OLS } & 5.9 & 5.5 & 6.0 & 6.5 & 6.5 & 12.0 & 10.4 & 9.7 & 9.2 \\
\hline & 6.6 & 5.7 & 5.7 & 6.6 & 6.1 & 13.9 & 13.0 & 12.2 & 10.6 \\
\hline & 7.3 & 6.8 & 6.8 & 6.9 & 6.9 & 12.5 & 11.6 & 10.8 & 10.2 \\
\hline & 1.3 & 1.5 & 1.9 & 2.0 & 2.3 & 5.4 & 4.4 & 3.6 & 3.3 \\
\hline \multirow[t]{3}{*}{$\mathrm{OLS}+\mathrm{Sh}$} & 2.1 & 2.0 & 2.0 & 2.8 & 3.0 & 7.4 & 7.8 & 6.8 & 7.2 \\
\hline & 3.6 & 3.2 & 3.5 & 3.4 & 3.7 & 7.0 & 5.6 & 5.4 & 5.2 \\
\hline & 2.9 & 2.1 & 2.0 & 2.1 & 1.9 & 10.6 & 6.9 & 4.9 & 4.2 \\
\hline \multirow{3}{*}{$\mathrm{GLS}+\mathrm{Sh}$} & 3.7 & 2.7 & 2.3 & 2.6 & 2.7 & 13.7 & 10.8 & 9.2 & 7.9 \\
\hline & 5.0 & 3.4 & 3.2 & 3.0 & 3.4 & 14.1 & 10.1 & 8.5 & 8.1 \\
\hline & 2.3 & 1.5 & 1.2 & 2.5 & 3.0 & 16.7 & 9.1 & 5.6 & 3.9 \\
\hline \multirow[t]{3}{*}{ ML } & 2.5 & 1.2 & 1.0 & 1.3 & 2.5 & 19.1 & 13.3 & 10.3 & 8.3 \\
\hline & 4.5 & 2.7 & 2.1 & 2.6 & 3.2 & 18.4 & 13.1 & 9.3 & 9.1 \\
\hline & 3.3 & 2.8 & 2.9 & 3.1 & 3.3 & 9.0 & 7.9 & 7.1 & 6.1 \\
\hline \multirow[t]{2}{*}{ GMM } & 3.2 & 2.8 & 2.5 & 3.1 & 3.4 & 9.9 & 9.2 & 9.9 & 9.5 \\
\hline & 3.9 & 4.0 & 3.8 & 3.6 & 4.0 & 9.9 & 10.7 & 10.1 & 9.2 \\
\hline \multirow[t]{2}{*}{ GMM1lag } & 1.9 & 2.3 & 2.7 & 2.3 & 2.6 & 4.7 & 7.2 & 7.9 & 8.0 \\
\hline & \multicolumn{5}{|c|}{$\begin{array}{l}\text { Set I: Test the null } \gamma_{R M}=0.0 \\
\text { when } \gamma_{R M}=0.0046\end{array}$} & \multicolumn{4}{|c|}{$\begin{array}{c}\text { Set II: test the null } \gamma_{R M}=0.0 \\
\text { when } \gamma_{R M}=0.0181\end{array}$} \\
\hline \multirow{4}{*}{ OLS } & 11.8 & 12.8 & 15.9 & 18.9 & 21.8 & 27.2 & 41.7 & 62.4 & 84.2 \\
\hline & 13.7 & 15.0 & 16.0 & 17.0 & 18.7 & 23.3 & 31.0 & 43.2 & 58.4 \\
\hline & 14.3 & 15.3 & 17.5 & 20.0 & 21.4 & 21.3 & 29.7 & 43.2 & 62.9 \\
\hline & 3.3 & 4.6 & 6.1 & 8.1 & 9.6 & 10.9 & 21.5 & 43.6 & 73.0 \\
\hline \multirow[t]{3}{*}{$\mathrm{OLS}+\mathrm{Sh}$} & 3.7 & 5.1 & 6.4 & 8.2 & 10.6 & 8.2 & 15.0 & 29.0 & 48.0 \\
\hline & 4.8 & 5.7 & 8.1 & 10.4 & 11.9 & 5.7 & 11.9 & 24.4 & 47.3 \\
\hline & 8.2 & 8.4 & 8.5 & 9.9 & 11.5 & 17.4 & 27.9 & 51.2 & 81.5 \\
\hline \multirow[t]{2}{*}{$\mathrm{GLS}+\mathrm{Sh}$} & 8.3 & 8.5 & 9.0 & 9.9 & 10.8 & 13.4 & 19.0 & 33.3 & 55.5 \\
\hline & 9.2 & 8.8 & 10.7 & 12.8 & 14.9 & 11.7 & 17.5 & 31.5 & 55.4 \\
\hline
\end{tabular}


Table 3. cont.

\begin{tabular}{|c|c|c|c|c|c|c|c|c|c|}
\hline \multirow{3}{*}{ ML } & & & & & & 27.4 & 39.2 & 56.8 & 82.9 \\
\hline & - & - & - & - & - & 18.5 & 26.7 & 38.8 & 58.6 \\
\hline & & & & & & 17.5 & 24.3 & 37.6 & 58.2 \\
\hline \multirow{3}{*}{ GMM } & 9.1 & 8.9 & 10.0 & 11.4 & 13.9 & 24.7 & 37.0 & 60.5 & 86.3 \\
\hline & 8.0 & 8.2 & 8.8 & 11.3 & 12.7 & 17.3 & 24.5 & 37.1 & 59.5 \\
\hline & 11.0 & 11.2 & 12.4 & 14.5 & 16.5 & 16.2 & 22.4 & 37.0 & 59.1 \\
\hline \multirow[t]{2}{*}{ GMM1lag } & 10.6 & 10.2 & 11.1 & 12.4 & 15.0 & 20.2 & 27.2 & 41.7 & 66.2 \\
\hline & \multicolumn{5}{|c|}{$\begin{array}{c}\text { Set I: Test the null } \gamma_{S M B}=0.0 \\
\text { when } \gamma_{S M B}=0.0068\end{array}$} & \multicolumn{4}{|c|}{$\begin{array}{l}\text { Set II: Test the null } \gamma_{H M L}=0.0 \\
\text { when } \gamma_{H M L}=0.0192\end{array}$} \\
\hline \multirow{3}{*}{ OLS } & 56.5 & 77.1 & 93.9 & 99.6 & 100 & 92.7 & 99.4 & 100 & 100 \\
\hline & 43.4 & 58.6 & 76.9 & 95.2 & 97.5 & 71.5 & 90.5 & 98.7 & 99.9 \\
\hline & 43.5 & 57.9 & 75.5 & 91.3 & 96.8 & 71.4 & 89.2 & 98.0 & 99.9 \\
\hline & 26.6 & 49.7 & 80.3 & 98.1 & 99.9 & 85.8 & 99.3 & 100 & 100 \\
\hline \multirow[t]{3}{*}{$\mathrm{OLS}+\mathrm{Sh}$} & 15.7 & 28.7 & 51.0 & 79.2 & 92.6 & 54.3 & 85.0 & 98.4 & 99.9 \\
\hline & 18.8 & 31.6 & 51.8 & 77.9 & 91.2 & 54.5 & 82.8 & 97.6 & 99.9 \\
\hline & 32.6 & 56.6 & 83.8 & 98.7 & 100.0 & 95.2 & 100 & 100 & 100 \\
\hline \multirow[t]{3}{*}{$\mathrm{GLS}+\mathrm{Sh}$} & 19.7 & 33.3 & 56.2 & 84.4 & 95.3 & 74.6 & 94.7 & 99.8 & 100 \\
\hline & 23.2 & 34.7 & 56.0 & 81.6 & 93.1 & 69.8 & 90.0 & 99.0 & 100 \\
\hline & 30.2 & 53.9 & 83.9 & 98.6 & 99.9 & 94.8 & 99.9 & 100 & 100 \\
\hline \multirow[t]{3}{*}{ ML } & 17.4 & 31.8 & 56.4 & 83.5 & 95.0 & 73.9 & 94.3 & 99.7 & 100 \\
\hline & 17.2 & 31.4 & 51.7 & 79.5 & 91.7 & 70.2 & 90.7 & 99.2 & 100 \\
\hline & 32.2 & 56.0 & 83.6 & 98.7 & 99.9 & 95.1 & 100 & 100 & 100 \\
\hline \multirow[t]{2}{*}{ GMM } & 20.8 & 33.6 & 57.1 & 84.2 & 95.2 & 74.4 & 94.4 & 99.8 & 100 \\
\hline & 22.7 & 34.9 & 56.2 & 81.2 & 93.2 & 70.3 & 90.4 & 99.3 & 100 \\
\hline GMM1lag & 21.6 & 34.3 & 55.9 & 83.6 & 94.9 & 73.6 & 93.5 & 99.6 & 100 \\
\hline
\end{tabular}

For Set I, the percentage rejection of the null $\gamma_{0}=0$ in the case of the OLS test used is larger than $5 \%$, whereas the other estimators produce a test size less than 5 percent, regardless the scenario. When the null hypotheses concerns the parameters: $\gamma_{S M B}, \gamma_{H M L}$ the OLS test also tends to reject the null hypothesis. Therefore, the usefulness of this method might be questionable. A detailed study of testing the true null hypothesis that a given parameter is zero, is presented only for Set II in Appendix, Table 4. The results of GLS + Sh and GMM tests are comparable. The ML test is slightly weaker than the GLS + Sh and the GMM tests and the OLS + Sh test is the weakest. In the third scenario, it can be noticed that the test based on the GMM1lag method is more powerful only for very large sample.

For small samples all used tests seem to be very weak. The rate of rejection false null hypothesis was more than 95 percent when the sample is really big (close to 480).

The results of the test power studies results when input parameters are taken from Set II is slightly different. Hence, while the true null $\gamma_{0}=0$ is tested the rejection rate of all used tests is large more than 5 percent, particularly in the second and third scenarios. In the case of a false null hypothesis concerning $\gamma_{R M}, \gamma_{S M B}$ or $\gamma_{H M L}$, the OLS test also tends to reject the null hypothesis. The power of the GLS + Sh and GMM tests is comparable, the ML test is weaker than these tests and the OLS + Sh test was the weakest. In the third scenario the GMM1lag test is the strongest but only for the big sample. The tests comparison results are similar to the Set I discussion. However, to obtain the satisfactory results the smaller sample than in Set I is required.

Generally, the model assumptions impact on the test power of the used tests. They are the strongest in the first and the weakest in the third scenario. From this simulation 
study it can be concluded that the most trustworthy method seem to be the GMM and the GLS + Sh one regardless on the considered assumption of the model (15) and input parameters used to generate data. The utility of the GMM1lag test in the third scenario, is less than the GMM test utility since its weaknesses for small sample. The OLS estimator, despite of its small bias in the case of some parameters estimation, is little precise but the tests based on the OLS method tend to reject both the true and false null hypothesis. The ML method is sensitive the input parameters used to data generating.

\section{CONCLUSIONS}

This paper investigated the small sample properties of several methods for estimating risk premium parameters in the Fama-French three factor asset pricing model. The simulation study was performed to investigate the bias, the precision and power differences across the estimation methods in three considered scenarios: homoscedasticity, conditional heteroscedasticity and autocorrelation and conditional heteroscedasticity. Two sets of input parameters were considered to simulate returns, calibrated from real data from the Warsaw Stock Exchange.

Based on the obtained results, it can be concluded that the most trustworthy seem to be the GMM and the GLS + Sh methods, regardless on the considered assumption on the model. For small samples, all methods produced biased estimators and relatively big RMSE. The tests of parameters significance are very weak. From this fact implies that when all used methods produce a significant parameter, the probability that this parameter is differ from zero is very high. In contrary, in the case of intercept testing, where the significance level is overestimated, when all used methods produce an insignificant parameter, the probability that this parameter is zero is also very high.

\section{APPENDIX}

Table 4. The rates of rejection of the null hypothesis.

The significance level is $5 \%$

\begin{tabular}{|c|c|c|c|c|c|c|c|c|c|c|}
\hline \multirow[t]{2}{*}{ Method } & \multicolumn{10}{|c|}{$\mathrm{T}=36 \mathrm{~T}=60 \mathrm{~T}=120 \mathrm{~T}=240 \mathrm{~T}=480 \mathrm{~T}=36 \mathrm{~T}=60 \mathrm{~T}=120 \mathrm{~T}=240 \mathrm{~T}=360$} \\
\hline & \multicolumn{4}{|c|}{$\begin{array}{l}\text { Testing the null } \gamma_{0}=0.0 \\
\text { when } \gamma_{0}=0.012\end{array}$} & \multirow[b]{2}{*}{71.5} & \multicolumn{5}{|c|}{$\begin{array}{l}\text { Testing the null } \gamma_{R M}=0.0 \\
\text { when } \gamma_{R M}=0.0\end{array}$} \\
\hline \multirow{4}{*}{ OLS } & 32.8 & 34.3 & 42.1 & 55.0 & & 9.7 & 9.9 & 9.4 & 9.9 & 9.3 \\
\hline & 33.7 & 35.6 & 38.9 & 45.9 & 55.4 & 12.3 & 12.8 & 12.2 & 11.8 & 10.9 \\
\hline & 31.2 & 32.0 & 37.0 & 44.9 & 55.4 & 9.5 & 10.1 & 8.9 & 8.6 & 8.2 \\
\hline & 25.3 & 24.7 & 29.3 & 38.9 & 57.6 & 2.1 & 2.4 & 2.7 & 3.0 & 2.6 \\
\hline \multirow[t]{3}{*}{$\mathrm{OLS}+\mathrm{Sh}$} & 25.6 & 27.4 & 30.1 & 37.1 & 49.4 & 2.8 & 3.0 & 4.0 & 4.9 & 5.0 \\
\hline & 21.4 & 22.2 & 25.5 & 32.6 & 45.5 & 1.4 & 1.5 & 2.0 & 2.5 & 2.7 \\
\hline & 40.6 & 37.8 & 40.0 & 50.9 & 70.8 & 6.6 & 4.3 & 3.4 & 3.1 & 3.0 \\
\hline \multirow{2}{*}{$\mathrm{GLS}+\mathrm{Sh}$} & 42.9 & 39.5 & 42.1 & 47.3 & 60.3 & 6.0 & 5.5 & 4.8 & 5.1 & 5.0 \\
\hline & 38.9 & 35.9 & 37.3 & 44.9 & 57.6 & 5.8 & 4.5 & 3.6 & 3.7 & 3.9 \\
\hline
\end{tabular}


Table 4. cont.

\begin{tabular}{|c|c|c|c|c|c|c|c|c|c|c|}
\hline & \multicolumn{5}{|c|}{$\begin{array}{l}\text { Testing the null } \gamma_{0}=0.0 \\
\text { when } \gamma_{0}=0.012\end{array}$} & \multicolumn{5}{|c|}{$\begin{array}{l}\text { Testing the null } \gamma_{R M}=0.0 \\
\text { when } \gamma_{R M}=0.0\end{array}$} \\
\hline \multirow{4}{*}{ ML } & 45.2 & 38.2 & 35.9 & 45.6 & 65.3 & 12.7 & 10.1 & 6.7 & 4.1 & 4.0 \\
\hline & 45.6 & 41.9 & 41.3 & 45.5 & 57.0 & 9.2 & 8.5 & 8.7 & 6.8 & 5.8 \\
\hline & 43.3 & 38.1 & 37.0 & 41.5 & 54.3 & 7.4 & 7.8 & 7.2 & 5.8 & 4.6 \\
\hline & 27.1 & 32.4 & 42.8 & 57.9 & 78.3 & 8.8 & 7.9 & 6.1 & 5.4 & 4.7 \\
\hline \multirow[t]{2}{*}{ GMM } & 26.0 & 32.3 & 39.8 & 50.3 & 64.7 & 8.2 & 7.4 & 6.7 & 6.6 & 5.8 \\
\hline & 24.7 & 29.2 & 36.2 & 46.2 & 60.3 & 7.5 & 6.3 & 5.1 & 4.8 & 4.5 \\
\hline GMM1lag & 10.6 & 18.3 & 32.1 & 44.7 & 61.9 & 1.4 & 1.9 & 3.0 & 3.6 & 4.3 \\
\hline \multicolumn{6}{|c|}{$\begin{array}{l}\text { Testing the null } \gamma_{H M L}=0.0 \\
\text { when } \gamma_{H M L}=0.012\end{array}$} & \multicolumn{5}{|c|}{$\begin{array}{l}\text { Testing the null } \gamma_{S M B}=0.0 \\
\text { when } \gamma_{S M B}=0.0\end{array}$} \\
\hline \multirow{3}{*}{ OLS } & 8.3 & 8.6 & 8.7 & 9 & 10.8 & 11.7 & 11.7 & 12.0 & 12.2 & 12.2 \\
\hline & 11.8 & 11.8 & 10.5 & 9.7 & 9.7 & 14.3 & 13.9 & 12.9 & 12.4 & 11.3 \\
\hline & 12.8 & 13.9 & 13.4 & 13.6 & 13.4 & 15.7 & 16.8 & 16.4 & 16.2 & 15.3 \\
\hline & 1.9 & 2.4 & 2.6 & 2.5 & 2.6 & 2.2 & 2.7 & 2.6 & 2.7 & 2.5 \\
\hline \multirow[t]{3}{*}{$\mathrm{OLS}+\mathrm{Sh}$} & 1.9 & 2.4 & 3.0 & 3.2 & 3.3 & 2.4 & 2.4 & 2.2 & 2.8 & 2.9 \\
\hline & 3.5 & 3.9 & 4.7 & 4.8 & 5.2 & 4.3 & 4.7 & 4.6 & 4.6 & 5.0 \\
\hline & 3.1 & 2.8 & 3.0 & 2.5 & 2.9 & 2.9 & 2.8 & 2.8 & 2.4 & 2.2 \\
\hline \multirow[t]{3}{*}{$\mathrm{GLS}+\mathrm{Sh}$} & 3.4 & 3.2 & 3.0 & 2.7 & 2.8 & 2.9 & 2.7 & 2.7 & 2.9 & 2.7 \\
\hline & 6.2 & 6.3 & 6.6 & 6.4 & 6.8 & 5.5 & 5.3 & 5.1 & 5.3 & 5.0 \\
\hline & 3.3 & 3.2 & 2.5 & 2.5 & 2.4 & 2.9 & 2.5 & 2.5 & 2.7 & 2.5 \\
\hline \multirow[t]{3}{*}{ ML } & 3.3 & 2.9 & 2.8 & 2.6 & 3.1 & 3.1 & 3.1 & 2.4 & 2.7 & 2.8 \\
\hline & 6.6 & 6.4 & 6.4 & 6.5 & 6.2 & 5.3 & 5.3 & 5.0 & 5.0 & 4.6 \\
\hline & 3.7 & 3.0 & 3.2 & 3.0 & 3.0 & 2.9 & 3.0 & 2.5 & 2.5 & 2.7 \\
\hline \multirow[t]{2}{*}{ GMM } & 3.1 & 3.2 & 3.0 & 2.8 & 3.0 & 2.9 & 3.0 & 2.8 & 2.9 & 2.6 \\
\hline & 6.6 & 6.5 & 6.6 & 6.3 & 6.6 & 5.0 & 5.6 & 5.5 & 5.1 & 5.0 \\
\hline GMM1lag & 6.2 & 5.5 & 5.0 & 4.2 & 4.1 & 4.5 & 4.1 & 3.8 & 3.2 & 3.0 \\
\hline
\end{tabular}

\section{REFERENCES}

Amsler, C.E., Schmidt, P., 1985. A Monte Carlo investigation of the accuracy of multivariate CAPM tests. Journal of Financial Economics, 14, pp. 359-375.

Andrews, D.W.K., 1991. Heteroscedasticity and Autocorrelation Consistent Covariance Matrix Estimation. Econometrica, 59, pp. 817-858.

Chen, R., Kan, R., 2004. Finite sample analysis of two-pass cross-sectional regressions. Working paper (University of Toronto).

Cochrane, J.H., 2001. Asset Pricing. Princeton University Press.

Czapkiewicz, A., Skalna, I., 2011. The performance of the Fama-French model for the Warsaw Stock Exchange boom and bust cycles. Bank $i$ Kredyt, 42, pp. 61-80.

Fama, E.F., MacBeth, J., 1973. Risk. Return and Equilibrium: Empirical Tests. Journal of Political Economy, 81, pp. 607-636.

Fama, E.F., French, K.R., 1993. Common Risk Factors in the Returns on Stocks and Bonds. Journal of Financial Economics, 33, pp. 3-56.

Fama, E.F., French, K.R., 1996. Multifactor Explanations of Asset Pricing Anomalies. Journal of Finance, 51(4), pp. 55-84.

Gibbons, M.R., 1982. Multivariate tests of financial models: A new approach. Journal of Financial Economics, 10 pp. 3-27.

Gibbons, M.R., Ross, S.A., Shanken, J., 1989. A Test of the Efficiency of a Given Portfolio. Econometrica, 57(5), pp. 1121-1152. 
Greene, W.H., 2008. Econometric Analysis. $7^{\text {th }}$ edition. Prentice Hall.

Hansen, L.P., 1982. Large Sample Properties of Generalized Method of Moments Estimators. Econometrica, 50(4), pp. 1029-1054.

Jensen, M.C., Black, F., Scholes, M.S., 1972. The Capital Asset Pricing Model: Some Empirical Tests. Studies in the Theory of Capital Markets, Praeger Publishers Inc.

Jagannathan, R., Wang, Z., 1998. An asymptotic theory for estimating beta-pricing models using cross-sectional regression. Journal of Finance, 57, pp. 2337-2367.

Kim, D., 1995. The Errors in the Variables Problem in the Cross-Section of Expected Stock Returns. Journal of Finance, 50, pp. 1605-1634.

Lettau, M., Ludvigsson, S., 2001. Consumption, aggregate wealth and expected stock returns. Journal of Finance, 56, pp. 815-850.

MacKinlay, A.C., Richardson, M.P., 1991. Using Generalized Method of Moments to Test Mean-Variance Efficiency. Journal of Finance, 46(2), pp. 511-527.

Maroney, N., Protopapadakis A., 2002. The Book-to-Market and Size Effects in a General Asset Pricing Model: Evidence from Seven National Markets. European Finance Review, 6, pp. 189-221.

Ogaki, M., 1993. Generalized Method of Moments: Econometric Applications. Handbook of Statistics, 11, pp. 455-485.

Schneider, T., Neumaier, A., 2001. Algorithm 808: Arfit-a Matlab package for the estimation of parameters and eigenmodes of multivariate autoregressive models. ACM T. Math. Software, 27, pp. 58-65.

Shanken, J., 1992. On the Estimation of Beta-Pricing Models. The Review of Financial Studies, 5, pp. 1-33.

Shanken, J., Zhou G., 2007. Estimating and Testing Beta Pricing Models: Alternative Methods and Their Performance in Simulations. Journal of Financial Economics, 84, pp. 40-86. 